Nevşehir Bilim ve Teknoloji Dergisi Cilt 5(2) 193-207 2016

DOI: 10.17100/nevbiltek.284742

URL: http://dx.doi.org/10.17100/nevbiltek.284742

\title{
Enerji Etkin Kognitif Radyo Ağları: Yeşil Ödeme
}

\author{
Mahir KUTAY ${ }^{1, *}$, H. Murat KARACA ${ }^{2}$, Tuncay ERCAN ${ }^{3}$ \\ ${ }^{1}$ Yaşar Üniversitesi, Müh. Fak. Elektrik-Elektronik Müh. Bölümü, İzmir \\ ${ }^{2}$ Turkcell İletişim Hizmetleri A.Ş, İzmir \\ ${ }^{3}$ Yaşar Üniversitesi, Müh.Fak., Bilgisayar Müh. Bölümü, İzmir
}

Öz

Kablosuz ve Mobil teknolojilerin gelişmesi, kullanım rahatlığından dolayı artan kullanıcı istekleri, multimedya uygulamalarının yoğun kullanımı, frekans sahasının verimsiz kullanılması Bilişsel Radyo (BR) olarak isimlendirilen yeni bir iletişim teknolojisi kavramının ortaya çıkmasına neden olmuştur. BR'ler bütün telsiz iletişim sistemlerinde frekans sahasının daha etkin ve enerji kullanımının da daha verimli olmasını sağlayacaktır. Bu çalışmada BR kavramsal olarak açıklanmış, sisteme ilişkin donanım ve yazılım problemleri özetlenmiş, iletişim ağlarıyla ilgili artan enerji maliyetleri, gittikçe ağırlaştırılan çevrebilim sınırlamalarına bağlı olarak BR’nin enerji etkin çalışmalardaki rolü incelenmiştir. Bu çalışmalar kapsamında, BR'ler enerji etkinliği ve yeşil iletişim temaları altında benzerliklerine göre gruplandırılmış ve özellikle Yeşil iletişimdeki BR katkıları için "Yeşil Ödeme" isimli bir algoritma önerilmiştir. Önerilen Yeşil Ödeme algoritmasında frekans sahasının ikincil kullanıcıları haberleşme güç seviyelerine göre yüksek ve düşük güçlü kullanıcılar olarak ayrılmış, belli bir eşik değerin üstündeki yüksek güçlü kullanıcılara yaptırım olarak ek bir maliyet getirilerek kanal alımları zorlaştırılmıştır. Böylece toplam kullanılabilir kanal yüzdesi düşürülmüş ve harcanan güç miktarında azalma sağlanarak BR'lerin yeşil iletişime katkısı gösterilmiştir.

Anahtar Kelimeler: Yeşil iletişim, yeşil ödeme, bilişsel radyo, BR, enerji ve frekans sahası verimliliği.

\section{Energy Efficient Cognitive Radio Networks: Green Payment}

\begin{abstract}
Development of mobile and wireless technologies, increasing user demands due to the ease of use, intensive use of multimedia applications and the inefficient use of frequency spectrum enable the emergence of a new communication paradigm, namely Cognitive Radios (CR). The use of CRs will provide effective use of spectrum and efficient energy management in all wireless communication systems. In this study, we've explained the concept of CR, summarized hardware/software difficulties of the system and examined the role of CRs in energy efficient studies due to the continuous increase of energy costs and tightened ecological regulations in transmission networks. Within the scope of these studies, CRs have been categorized into groups of different similarities under the theme of green communication and energy efficiency and particularly proposed a "Green Payment" algorithm for the contributions in green communications. In the proposed "Green Payment" algorithm, secondary users of the frequency spectrum have been separated into high power and low power users according to the transmitting power levels. It has brought an additional cost for the high power users above a certain threshold value and made more difficult to purchase a free channel. This paper shows how our algorithm has achieved a considerable amount of power reduction while the total percentage of available channels falls down.
\end{abstract}

Keywords: Green communications, green payment, cognitive radio, CR, energy and spectrum efficiency.

* e-mail: mahir.kutay@yasar.edu.tr 
1. Giriş

Özellikle kablosuz ve mobil teknolojilerin gelişmesiyle birlikte artan kullanıcı sayısı, multimedya uygulamalarına olan yoğun talep yüksek veri hızlarına olan ihtiyaçları da arttırmıştır. Yüksek bant genişliği sağlayan mevcut kablosuz iletişim sistemleri tarafından kullanılmakta olan lisanslı/lisanssız sabit frekans atama mekanizmaları, sınırlı radyo frekans sahası nedeniyle ihtiyacı karşılayamamaktadır. Frekans sahasını daha verimli kullanabilecek yöntem ve teknolojilerden biri olan Bilişsel Radyo (BR) sistemleri, lisanslı kullanıcılar tarafından kullanılmayan frekansların başkaları tarafından geçici kullanımına olanak tanıyarak frekans sahası sıkışıklığı problemine çözüm getirmektedir [1], [2], [3]. BR sistemleri spektrumun sabit tahsislerle dağıtılması yerine daha verimli kullanılabilmesi için mevcut spektrum ortamının sürekli olarak sezilerek kullanılmayan veya yoğunluğu az olan lisanslı kanalların belirlenmesini ve uygun kanalların lisanssız ikincil kullanıcılara tahsisini öngören bir radyo teknolojisi kullanırlar [4]. Ayrıca tahsis edilen kanalların birbirleriyle girişimlerini önler, farklı işlevler için gerekli sistem parametrelerini dinamik ve bağımsız şekilde ayarlayabilirler [5].

Bir BR şebekesinde hedeflenen, çalışan frekans kanalları üzerinde yasal kullanım hakkına sahip olan birincil kullanıcılar (BK) üzerinde herhangi bir girişim oluşturmadan firsatçı bir biçimde söz konusu spektrumun ikincil kullanıcılar (İK) tarafindan kullanılmasıdır. Bu yüzden, ikincil kullanıcılar frekans sahasının birinciller tarafından kullanılıp kullanılmadığını, içinde bulunulan fiziksel ortama, mevcut kullanılmakta olan kanalların durumuna, zamana, kullanıcı sayısına ve tercihlerine ya da gerekirse maliyet koşullarına göre algılayıp kullanımına karar verebilecek yapay zekâ teknikleri kullanabilme yeteneğine sahip olmalıdırlar [6], [7]. Ayrıca farklı kablosuz teknolojilerin kullanıldığı BR ağlarda, kullanıcıların farklı beklentileri olan, ağın kendisine ve kullanılan cihazlara özgü frekans, bant genişliği, gönderme gücü, modülasyon çeşidi, bit hata oranı gibi hizmet kalitesini etkileyebilecek unsurlar da bu değerlendirme içinde yer almalıdır. BR sistemlerinin hücresel, algılayıcı ve yapısız (ad hoc) ağlar gibi farklı kablosuz ağ teknolojilerinde kullanıldığı düşünüldüğünde, özellikle mobil ve küçük cihazlara özgü enerji etkinliği, enerji maliyetleri gibi parametreler, gittikçe yaygınlaşan ve yükseltilen çevrebilimle ilgili sınırlamalar nedeniyle ortaya çıkmış olan yeşil haberleşme kavramı kapsamında da incelenebilir.

\subsection{Bilişsel Radyo ve Yeşil İletişim İlişkisi}

Bilişsel radyolar ve yeşil iletişim hakkındaki mevcut akademik çalışmalardan elde edilen bilgiler artan enerji maliyetleri, yeşil iletişimdeki yüksek çevresel standartlar nedeniyle, kablosuz iletişim sistemlerinde enerji verimliliğinin önemini ortaya çıkarmıştır [8]. Yeşil iletişim, mevcut kaynakları verimli kullanan, çevreye duyarlı ve enerji tasarrufu sağlayan iletişim sistemlerini içermektedir. BR, amacı itibariyle frekans sahasının bilinçli kullanımıyla kullanıcı ihtiyaçlarını karşılamaya çalışır. BR yeşildir, çünkü tüketici durumundaki son kullanıcılar için sınırlı sayıdaki lisanslı frekans kaynaklarının yönetimi ile enerji verimliliği, enerji tasarrufu ve elektromanyetik yayılım gibi çevre üzerinde doğrudan etkisi olan sorunları çözmeye çalışır. Kablosuz sistemlerde frekans kullanım lisansı olmayan İK'ların işlevlerinden birisi olan frekans sahası algılama, temel olarak, BK'ların frekans kullanım önceliğini sağlamakla ilgili olduğu için, frekans tarama zamanının bütün sistem verimliliği ve enerji tüketimi açısından en küçüklenmesi hedeflenmiştir [9], [10]. 
Yeşil iletişim konusu bütün kablosuz iletişim teknolojilerine uygulanabilir. Bunun amacı sadece çevreyle ilgili olarak fosil yakıtlar tarafindan ortama bırakılacak olan $\mathrm{CO}_{2}$ (karbondioksit)'nin ötesinde sınırlı bir kaynak olan frekans spektrumunun uygun olarak kullanılabilmesidir. Palicot çalışmasında, BR’yi yeşil iletişim için uygun bir teknoloji olarak önermiş, kullanılan hesaplama algoritmalarının etkinliği, antenlerin sinyal yayımını, gönderme gücü yönetimini veya kablosuz sistemlerin ayrı veya merkezi yapıda tesis edilmesinin olası etkilerini tartışmıştır. Özellikle elektromanyetik yayılımın azaltılması için BR'nin kolayca kullanılabileceğini vurgulamıştır [11].

BR'deki güvenlikle ilgili hususlar bu çalışmanın kapsamı dışında tutulmuş olup, diğer bölümler şu şekilde düzenlenmiştir: Bölüm 2'de günümüze kadar yapılmış olan mevcut çalışmalar kategorize edilmek suretiyle incelenmiş, öncelikle BR ağların temel problemlerini içeren çalışmalar irdelenmiştir. Üçüncü bölümde bu problemlere çözüm getiren çalışmalar özetlenerek her birinin bilimsel katkıları ve eksik yanları tartışılmıştır. Dördüncü bölümde Yeşil iletişimdeki BR katkıları için önerilen "Yeşil Ödeme" algoritması açıklanmıştır. Son bölümde ise çalışma sonuçları ana hatları ile verilmiş ve gelecekte yapılabilecek potansiyel çalışmalara ilişkin beklentiler açıklanmıştır.

\section{2. Önceki Çalışmalar}

Bugüne kadar yapılan birçok çalışmada düşük enerjili, yüksek performanslı BR sistemlerini tasarlayabilmek için, algılama ve iletim arasındaki ödünleşim incelenmiştir. Bu çalışma kapsamında ulaşılabilen ve incelenen kognitif radyolar, enerji etkinliği ve yeşil iletişim temaları altındaki bilimsel kaynaklar, odaklandıkları konulara ve benzerliklerine, mümkün olduğunca da tarihlerine göre aşağıdaki gibi gruplandırılmıştır:

- GP1-BR mimarisi, kullanımı ve önemli işlevleri

- GP2-Frekans spektrumunun algılanmas1 ve tahsisi

- GP3-Farklı hesaplama algoritmalarının etkinliği

- GP4-Yapay Zekâ Teknikleri kullanımı

- GP5-Yönlendirme protokollerindeki enerji etkinliği

- GP6-Yeşil BR ağlar ve algılayıcı cihaz kullanımı

- GP7-Enerji yönetimi

\subsection{BR Mimarisi, Kullanımı ve Önemli İşlevleri}

Birinci bölümde açıklanan temel hususlar 1şığında BR ağlardaki lisanslı (birincil) ve lisanssız (ikincil) kullanıcılar arasındaki fonksiyonel ilişki şu şekildedir [12]:

- Lisanslı kullanıcılar, lisanssız kullanıcılardan habersizdirler,

- Lisanssız kullanıcılar, lisanslı kullanıcıları rahatsız etmeden, girişim yaratmadan kanallarını kullanıp kullanmadıklarını tespit edebilmelidirler,

- Bulunan boş kanal kullanılmalı, ancak lisanslı kullanıcı kanala döndüğü zaman hemen kanalı boşaltabilmelidir,

- İletişim ortamı tekrar dinlenerek yukarıdaki adımlar bir döngü olarak takip edilebilmelidir.

$\mathrm{Bu}$ durum frekans sahasının; (1) algılanması, kullanıcı bilgilerinin sezilmesi, (2) yönetimi, (3) paylaşımı ve (4) değiştirilebilirliği gibi akıllı işlevleri zorunlu kılmaktadır. Spektrum sezme, BR 
sistemlerinin en önemli fonksiyonudur. Bu yüzden şimdiye kadar yapılan birçok bilimsel çalışmada, iletişim ağları katmansal mimarisinde kablosuz ortamı ve kullanımını içeren "fiziksel" ve "veri linki" katmanlarında uygulanabilecek farklı yöntemler üzerinde durulmuştur. "Spektrum yönetimi”, lisanssız kullanıcıların ortam sezinlemesiyle buldukları kanalların kalitelerini değerlendirerek uygun kanalı seçmeleridir. "Spektrum paylaşımı" ise seçilen boş kanalda diğer lisanssız kullanıcılara ilişkin koordinasyonun sağlanması ve ortak paylaşımın sağlanmasıdır. "Spektrum değiştirme" lisanslı kullanıcıların tekrar kanala döndüklerinde kanalın boşaltılması ve BR temel döngüsüne tekrar dönmektir. $\mathrm{Bu}$ fonksiyonları yerine getirebilmek için spektrum sezme teknikleri kullanılarak spektrumda belli bir yerde ve zamanda kullanılmayan bantlar algılanabilir. Bu şekilde BR sistemleri mevcut paylaşılan bu ortama göre farklı frekanslarda çalışmak, modülasyon türü, ortam erişimi ve iletişim gücü gibi çalışma parametrelerini en uygun düzeyde sağlayacak şekilde değiştirebilir [13-15]. Birincil kullanıcılara ait mevcut boş frekans sahasını tespit edebilmek ve bu işlevi enerji etkin bir yöntemle yapabilmek için, Grace ve diğerleri tarafından, yeşil bilişsel radyo tabanlı sistemleri tasarlama ve kullanma yöntemlerini incelemiş̧lerdir [16]. Yazarlar kanal kullanım olasılığını hesaba katarak, kanal tayini ve mevcut frekans sahasını belirleyip, modülasyon seviyesini ayarladıkları değişken bir modülasyon stratejisi ile frekans sahası tarama ihtiyacını azaltıp dolayısıyla da enerji tasarrufu sağlamışlardır.

\subsection{Frekans Spektrumunun Algılanması ve Tahsisi}

Akyıldız ve diğerleri tarafından spektrum algılama, kullanım kararı verme, frekans paylaşımı ve hareketliliği fonksiyonları açıklanmış ve gelecekteki araştırma konuları belirtilirken [17], çoklu BR ağlarda spektrum algılamada en çok dikkat edilmesi gereken konunun enerji etkin ve performanslı olarak çalışabilmesi kaynak [18] ve [19]'da irdelenmiştir. Namboodiri [20]' de isimli çalışmasında BR şebekesinde kolay kanal erişimi ile daha az enerji tüketilmesine ilişkin hususların önceki çalışmalarda incelenmediğini vurgulamış, aynı zamanda frekans sahası taramanın da önemli derecede güç tüketen bir işlem olduğunu ifade etmiştir. Çalışmasında bir BR ağının geleneksel bir kablosuz Adhoc ağı senaryosuna göre daha enerji verimli olduğunu göstermiştir.

İK'ların lisanslı BK'lar üzerinde yarattıkları karışım (interference) etkisi kullanılacak frekans bandının etkinliği açısından çok önemlidir. [21]'de sunulan işbirlikçi algılama yönteminde frekans algılama zamanı ve gecikmesi, kanal problemleri, kanal kontrolü ve raporlama, kullanıcı seçimi, enerji ve işbirliği etkinliği, hareketlilik, güvenlik gibi bileşenler ayrıntılı olarak incelenmiştir. BR ağlardaki spektrum algılama fonksiyonlarının fazla çalışması daha fazla güç tüketimi anlamına gelmektedir. Buna paralel olarak yapılan çalışmalarda işbirlikçi frekans sahası algılamada enerji ve şebeke çıktısı arasındaki ödünleşim irdelenmiş, güvenilirlik kısıtları altında ikincil kullanıcılara istedikleri frekans spektrumu sağlanırken algılama sürecinde kullanılan enerjinin minimize edilmesine ilişkin çözüm geliştirilmiştir [22-23]. Tang ve diğerleri tarafından yapılan başka bir çalışmada BR ağlarda algılanmış olan spektrumun kullanıcılara dağıtılmasına ilişkin sistem performansı optimum tutulurken, enerji verimliliği de iyileştirilmeye çalışılmıştır [24]. 


\subsection{Farklı Hesaplama Algoritmalarının Etkinliği}

BR cihazlarının yazılım desteğine ilişkin olarak, Bourbia ve diğerleri tarafından, kullanıcı tarafından istenildiğinde açıp/kapatılabilecek, mevcut telsiz sinyal ortamını karakterize edecek bazı ölçütlerle kullanılacak kanalın kalitesi ile ilgili istatistiksel değerlendirmeler sağlayacak bir dengeleyici arayüz açıklanmış ve böylece İK'ların uygun spektrumu daha kısa sürede algılanmasının sağlanabileceği belirtilmiştir [25]. Zhao ve diğerleri de frekans sahası algılama sürecinde;

(1) SNR (sinyal-gürültü oranı) yüksekse veya BK yoksa tek adımlı frekans sahası algılama uygulanarak, algılama süresi ve enerjiden tasarruf sağlanması,

(2) Çalışma sahasına ilişkin yerel keşif kararlarının kullanılması gibi iki farklı adım içeren iki adet enerji verimli işbirlikçi frekans sahası algılama yöntemi önermişlerdir [26].

BR ağlarda kanalların daha etkin kullanılmasını sağlayan OFDM halen incelenmekte olan bir konu olmasına rağmen [27]'de OFDM kullanmak suretiyle frekans sahası kullanım verimliliği arttırılırken, aynı anda enerji verimliliğini de optimize edebilmek için çok amaçlı bir kaynak paylaşım problemi irdelenmiştir. [28]' de de kapalı ortamlarda GSM sistemleri üzerinden internet kullanımını mümkün kılan "femtocell”'ler için BR ağlara benzer şekilde uygun kanal erişimi ve kullanımı, enerji verimliliği ve performansa ilişkin algoritmalar önerilmiştir. BR ağların yüksek kapasiteli spektrum seçimi için kullanıcılara imkân vermesi sebebiyle birincil kullanıcıların aktivitesi, ikincil kullanıcıların dağılımı ve spektrum yapısı hesaba katılarak geliştirilen, özellikle çoklu-ortam servisleri, dosya kullanımı gibi kullanıcıların farklı ihtiyaçlarını karşılayan QoE tabanlı bir network modeli Wenjuan ve diğerleri tarafindan önerilmiştir [29].

\subsection{Yapay Zekâ Teknikleri Kullanımı}

BR ağlarda spektrum algılaması, analizi ve tahsisi gibi ölçümlerde daha doğru karar verilebilmesi için öğrenme algoritmalarının kullanımına önem verilmeye başlanmış, yapay sinir ağlarının kullanımı gündeme gelmiştir [30]. Bu çalışmada kullanılacak veri setlerinde kullanıcı cihazlarına, network kartlarına ve network trafiğine ilişkin bilgiler kullanılmış, veri hızı değişiklikleri için BR cihazı yapılandırmasının sağlayacağı faydalar tartışılmıştır. İletişim ortamı son derece dinamik olan kablosuz/hareketli ağlarda yönlendirme protokollerinin oldukça yüksek performans ihtiyacı nedeniyle yapay zekâ uygulamalarına duyulan ihtiyaç oldukça fazladır. Quadir tarafından BR ağlarda farklı yapay zekâ uygulamalarına (Markov modelleri, Oyun Teorisi) ilişkin detaylı bir inceleme yapılmış ve özellikle de yönlendirme konusu tartışılmıştır [31]. Abbas ve diğerleri de bu çalışmanın ötesinde BR ağlarda spektrum tahsisi ve yönetimi için kullanılan yapay zekâ ve makine öğrenmesi tekniklerini daha da genişleterek irdelemişlerdir [32]. Yazarlar bu derleme çalışmalarında ilk önce BR prensibini, temel kaynaklarını, parametrelerini ve hedeflerini vermişler, daha sonra yapay zekâ tekniklerinin öğrenme yöntemlerini, rollerini ve BR ağlardaki önemini tartışmışlardır. Makine öğrenmesi tekniklerinden birisi olan takviyeli öğrenme (Reinforcement Learning- $R L$ ) çalışma ortamındaki deneme-yanılma uygulamalarına dayanır. BR ağlardaki uygun spektrumun bulunması, etkin kullanılması gibi fonksiyonlarının bu yönteme uygun olarak incelenmesiyle ilgili bir çalışma Adhoc ağlar üzerinde Felice ve diğerleri tarafından yapılmıştır [33]. Yazarların BR ağlardaki yapay zekâ kullanımına ilişkin katkıları; 
(1) uyguladıkları yöntemin Adhoc ağlar üzerinde kullanımına ilişkin sağladığı faydalar ve eksiklikler, (2) spektrum seçimi ve yönlendirme, (3) kullanıcılar arasındaki girişime ilişkin değerlendirmelerdir.

\subsection{Yönlendirme Protokollerindeki Enerji Etkinliği}

Kullanılmayan frekans spektrumunun dinamik olarak lisanssız, İK'lara atandığı BR ağlarda, ağ yönetimi ve kontrol maksatlı mesajların kullanılması kaçınılmazdır. Ancak çalışılan ortamdaki kullanıcı ve kanal farklılıkları bu mesajların alınabilmesi için uygun bir kanal kalitesi ister. Özellikle de çokluatlama (multi-hop) gerektiren ağlarda uygun seçilmiş ölçütlere sahip yönlendirme protokolleri bu kalitenin gerçekleşmesine yardımcı olur [31], [34]. Cesana, Cuomo ve Ekici ise çalışmalarında BR ağlarda algılanan ve paylaşılan spektruma ilişkin bütün bilgileri kullanarak etkin yönlendirme protokolleri bulunmasını veya bunun için sadece girişim, minimum yönlendirme enerjisi, uygun bant genişliğinin kullanılması, gecikme ve etkin iletişim kullanımı gibi yerel spektruma ait parametre ve değerlerin kullanılmasını önermişlerdir [35]. Rao ve diğerleri, çalışmalarında bir BR şebekesinde verinin enerji verimli bir şekilde yönlendirilmesinde karşılaşılan zorluklara odaklanmışlar ve bu konuda yapılmış bazı çözüm önerilerini inceleyerek üzerinde çalışılması gereken konuları şu şekilde toparlamışlardır [36]:

- Servis kalitesi (QoS) desteği ile yönlendirme desteği

- Hata toleranslı yönlendirme

- Güvenilir yönlendirme (kötü amaçlı düğ̈̈mlerin olması durumunda enerjiyi korurken güvenli yollar boyunca verilerin yönlendirilmesi)

- Gerçekçi protokollerin geliştirilmesi (tasarlanan protokoller gerçek ortamlarda test edilmelidir).

\subsection{Yeşil BR Ağlar ve Algılayıcı Cihaz Kullanımı}

Yeşil BR ağların teması, mevcut kullanılmayan frekans spektrumu kaynaklarının verimli kullanılması, çevreye duyarlı ve enerji tasarrufu sağlayan iletişim sistemlerini (yazılım/donanım) içermesidir. BR ağların her katmanında, gerçek-zamanlı bilgi sağlamak için kullanılabilecek farklı algılayıcı cihazlardan gelen veriler, enerji verimliliğinin sürdürülebilirliği için en iyi kararların verilmesine yardımcı olacaktır. Palicot bu konuyu içeren çalışmasında BR ağların yeşil perspektifi üzerinde durmuş, kullanılan cihazların çevre duyarlılığını arttıracak olan algılayıcı cihazların farklı katmanlardaki kullanılışına, farklı katmanlardan gelecek bilgilerin çeşitliliğine ilişkin bilgiler vermiş̧ir [37-39]. Palicot ve diğerleri çalışmalarında yeşil BR’ye ulaşmak için oluşturdukları modelin farklı katmanlarında algılayıcıların nasıl dağıtılacağını açıklamışlar, güç tüketimiyle ilgili örnek algılayıcı uygulamaları ile enerji etkinliği için doğru karar verme ve geliştirme kısıtlarını irdelemişlerdir [40]. Gür ve Alagöz tarafından yapılan başka bir çalışmada BR ağların yeşil etkinliği ile ilgili olarak enerji etkinliğini arttırma ve enerji etkin çalışmada da BR cihaz özellikleri, donanım ve yazılım karmaşıklıkları, ağ bileşenleri ve protokoller ile farklı algoritma ve ödünleşim problemleri tartışılmıştır [41].

\subsection{Enerji Yönetimi}

BR ağlarda, İK'lar tarafindan yerine getirilen spektrum algılama, performans durumu ve BK'larla olabilecek en az girişim önemli zorluklar olarak ortaya çıkmaktadır. Kablosuz ve hareketli kullanıcıların bu fonksiyonları mevcut enerjileriyle gerçekleştirdikleri düşünüldüğünde enerji yönetiminin 
önemi ortaya çıkmaktadır. Li ve diğerleri veri linki ve fiziki katmanlar arasındaki enerji etkinliğini maksimize etmek için yaptıkları çalışmada, iletişim süresinin iyileştirilmesi ve BK'larla istenmeyen girişimin önlenmesi için gönderme gücünün sınırlandırılması üzerinde durmuşlardır [42]. Chen ve diğerleri tarafından yapılan başka bir çalışmada da İK'ların periyodik spektrum algılaması ve gönderme gücü ile harcanan enerji seviyesi oranlarına önem verilmiş, Markov modelleri kullanılarak mevcut enerji ile maksimum veri gönderimi sağlanmasına ilişkin politikalar geliştirilmiştir [43]. Ghadikolaei ve diğerleri, BR ağlarda mevcut enerji verimli frekans sahası algılama ve frekans değiştirme yaklaşımlarını incelemiş ve sınıflandırmış, enerji tüketimi ve kullanım verimliliği arasındaki ödünleşimi bir BR ağı tasarım parametresi olarak belirlemişlerdir [44]. Yazarlar ayrıca BR ağlardaki enerji etkin çalışmalarda hala araştırma yapılabilecek konuları (1) enerji etkinliğinde bütün kullanıcıların iyileştirilmesi, (2) dinamik enerji etkinliği tasarımı, (3) tekli, merkezi veya dağıtık ağ düzenleri için proaktif veya reaktif spektrum algilama ve spektrum değiştirme olarak belirlemişlerdir.

\section{3. Çalışmaların Değerlendirilmesi}

BR ağlarda şimdiye kadar yapılan akademik çalışmaların çoğu frekans sahası algılama, bulunan uygun kanalların paylaşımı, yönetimi ve frekans sahası erişimindeki enerji verimliliği ile ilgilidir. Bölüm 2'de, yedi farklı grup olarak kategorize edilmiş olan bu alanlar bir matris şeklinde Tablo 1'de verilmiştir. BR ağlar ve Yeşil iletişim konusunda temel bilgi verenler hariç olmak üzere, incelenen bütün makaleler odaklandıkları alana göre referans numaralarıyla gösterilmişlerdir.

Tablo 1. KR ağları çalışmalarının sınıflandırılması

\begin{tabular}{cccccccc}
\hline Çalışma & GP1 & GP2 & GP3 & GP4 & GP5 & GP6 & GP7 \\
alanları & $1-5$, & & & & & \\
GP1 & $13,14,15$ & & & & & \\
GP2 & & $17,20,21$ & $18,19,22,23,24$ & & & & \\
GP3 & 25 & & $26,27,28,29$ & & & \\
GP4 & & 32,33 & & 30 & 31 & & \\
GP5 & & & & & $34,35,36$ & & \\
GP6 & $37,38,39$ & & & & & 40,41 & \\
GP7 & 45 & & 44 & & & & 42,43 \\
\hline
\end{tabular}

Tabloda verilen bütün çalışmalarda frekans sahası algılama ve enerji verimliliği arasındaki ödünleşim konusu ön plana çıkmakta, bu konuya yönelik çözüm önerileri sunulmaktadır. BR şebekeleri için artan çoklu-ortam servislerini ve kullanıcı sayısını karşılayabilecek diğer bir ihtiyaç da geniş bantlı spektrum algılamadır. Bu ağlarda İK' lar geniş bir bant boyunca güvenli bir şekilde spektral olanakları keşfetmektedirler, Sun ve diğerleri tarafından önerilen geniş bantlı spektrum algılama algoritmaları [45]' de sunulmuş, fayda ve avantajlarına göre sınıflandırılmışlardır.

\section{Yeşil Ödeme Kavramı}

\subsection{Yeşil Ödeme Algoritması}

BK'lara ait lisanslı ancak kullanılmayan frekansların tespit edilerek enerji etkin bir şekilde lisanssız İK'lara tahsis edilmesine ve yönetilmesine ilişkin BR ağları kullanılma kavramı, yukarıda 
belirtilen farklı çalışmalarda yeterince irdelenmiştir. Daha önce yapılan bu çalışmalara örnek olacak şekilde farklı kanal tahsis ve kullanım yönteminin uygulandığı, diğer kullanıcılar üzerinde en az girişim yaratacak açık arttırmaya dayalı bir kanal atama algoritması [46]'da geliştirilmiştir. Bu makalede kullanılan frekanslara ilişkin girişim grafikleri ve açgözlü algoritma (greedy) ile mevcut spektrum ve İK listesi çıkarılmış ve uygun IK'lara açık artırma ile istedikleri frekans bandı ataması yapılmıştır. Başka bir çalışmada [47] da önceki bölümlerde açıklanmış olan BR ağlardaki enerji etkin yöntemlere örnek olacak şekilde yeşil iletişim kapsamında yeşil ödeme kavramı geliştirilmiştir. Yeşil ödeme kavramında İK'lar güç seviyelerine göre yüksek ve düşük güçlü kullanıcılar olarak ayrılmakta, yüksek güçlü kullanıcılara yaptırım olarak ek bir maliyet getirilmekte ve kanal alımları zorlaştırılmaktadır. [46]'da önerilmiş olan açık arttırma algoritmasına eklediğimiz yeşil ödeme kavramında İK'ların gönderme güçleri için bir eşik değer belirlenmiştir. Bu değerin üzerinde olan İK'lar yüksek güçlü kullanıcı olarak adlandırılıp açık arttırmada daha fazla fiyat önerseler bile kanalı almaları mümkün olmamaktadır. Eğer eşik seviyesinin altında iseler düşük güçlü kullanıcı olarak sınıflandırılıp kanal kullanım hakkı alabilmektedirler. Böylece bütün BR ağında harcanan toplam güç seviyesi düşürülmüş olmaktadır.

\subsection{Simülasyon Sonuçları}

Açık arttırmaya dayalı BR ağ modelinde BK'ların kullanmadığı frekanslar, ortamda bulunan bütün İK'ların kullanabileceği ortak bir spektrum havuzu oluşturur. Her bir İK'nın kendi taraması ile bulduğu ve oluşturduğu bu frekans havuzu temel girdi olacak şekilde kullanılır. Algoritmanın bundan sonraki basamakları şöyledir:

1. Frekansı kullanacak farklı İ' lardan birbirlerine uzaklıkları belli bir eşik değerinin altında olup olmamasına göre girişim çizgesi elde edilir.

2. Bu çizgeye göre bağlantı ihtiyacı olan İK' lar en az veya hiç kullanılmamış frekansları seçerek açık arttırmaya katılır. Ancak bazı kullanıcılar eşik değerinden yüksek olan iletişim güçleri nedeniyle, yüksek güçlü kullanıcı olarak adlandırılıp açık arttırmada daha fazla fiyat önerseler bile kanalı almaları mümkün olmamaktadır. Eşik değerin altındaki İK'lar ise düşük güçlü kullanıcı olarak sınıflandırılıp kanal kullanım hakkını alabilmektedirler.

3. Kanalların alınması: Buna göre klasik algoritmamızın 2. adımında iki node' dan (ana node ve komşu node) hangisi daha fazla fiyat öneriyorsa o kanalı alabilirken, yeni algoritmada eğer gücü eşik güç seviyesinin altında ise kanalı alabilmekte, aksi durumda kanalı alamamaktadır.

Klasik algoritmamızda toplam sistem çıktısının işaret girişim+gürültü oranı (SINR) eşik değerine göre değişimini alttaki gibi incelemiştik (şekil 1). Görüldüğü üzere SINR eşik değeri arttıkça servis kalitesi (QoS) baskısı arttığı için (birincil alıcı kullanıcı üzerinde izin verilebilen toplam girişim seviyesi düştüğü için) toplam kanal alım yüzdesi azalmakta ve kullanılabilen kanal sayısı azaldığı için sistem çıktısı düşmektedir. 


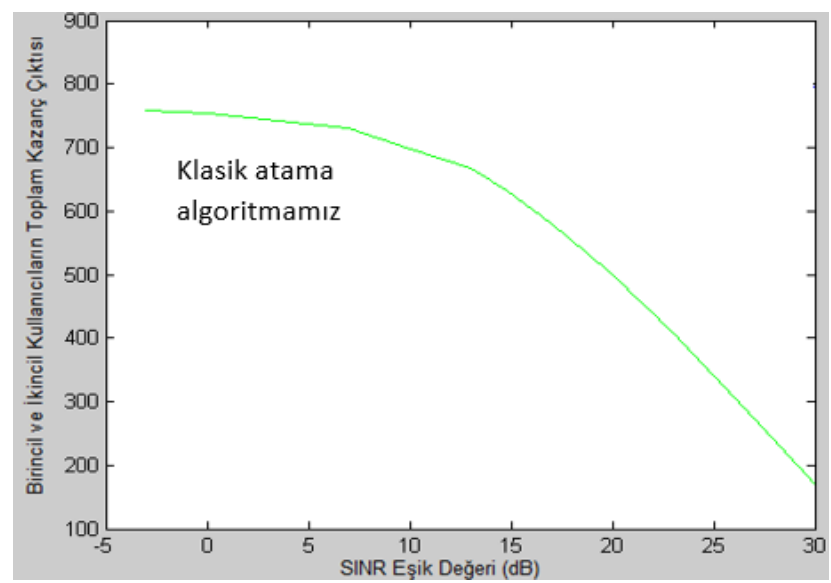

Şekil 1. Klasik algoritmada birincil ve ikincil kullanıcıların toplam kazanç çıktısının SINR eşik değerine göre değişimi

Yeni çalışmamızda öncelikle klasik algoritmamızla yeşil ödeme kısıtı altında toplam sistem çıktılarının değişimini karşılaştırdık. Simülasyonumuzda 2 adet birincil kullanıcı (birincil verici ve alıcı) ve 15 adet ikincil kullanıcının 1000mx1000 metre bir alanda aşağıdaki gibi rasgele dağıldığını varsaydık (şekil 2).

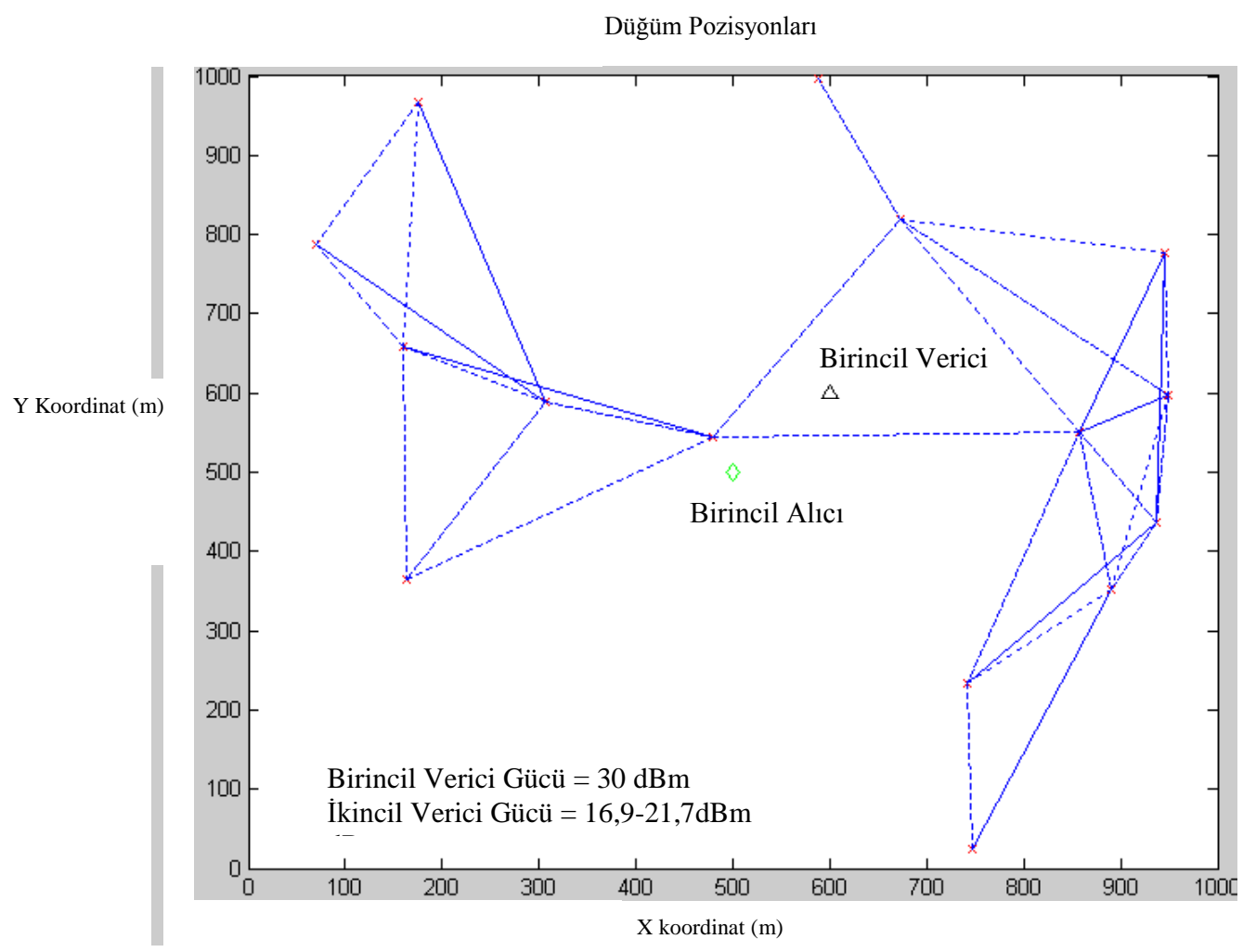

Şekil 2. Girişim Çizgesi, üçgen ve elmas birincil verici ve alıcıyı, x’ ler ikincil kullanıııları göstermektedir.

Birincil verici gücü $1000 \mathrm{~mW}$ iken ikincil kullanıcı güçlerinin 50 ile $150 \mathrm{~mW}$ arasında rasgele değiştiğini varsaydık. Ayrıca servis kalitesini belirleyen işaret, SINR oranı eşik değeri de -3 ile $30 \mathrm{~dB}$ arası değişecek şekilde toplam 12 deney koştuk. Buna göre simülasyonlarda kullandığımız parametreleri Tablo 2’ deki gibi toparlayabiliriz. 
Kutay M., Karaca HM., Ercan T.

Tablo 2. Simülasyon parametreleri

\begin{tabular}{|c|c|c|}
\hline Birincil kullanıcı gücü: & $\begin{array}{r}10 \\
62 \mathrm{~mW}, 72 \mathrm{~mW}, \mathbf{1 2 2} \\
\mathbf{1 3 9} \mathbf{~ m W}, 77 \mathrm{~mW}, 92\end{array}$ & $\begin{array}{l}\mathbf{1 1 6} \mathbf{~ m W}, \\
8 \mathrm{~mW}, 135\end{array}$ \\
\hline \multirow{12}{*}{ SINR Eşik dß (Girişim Hassasiyeti) } & 1. deney & $-3.01 \mathrm{~dB}$ \\
\hline & 2. deney & $0 \mathrm{~dB}$ \\
\hline & 3 deney & $6,99 \mathrm{~dB}$ \\
\hline & 4. deney & $10 \mathrm{~dB}$ \\
\hline & 5. deney & $13,01 \mathrm{~dB}$ \\
\hline & 6. deney & $14,77 \mathrm{~dB}$ \\
\hline & 7. deney & $16,99 \mathrm{~dB}$ \\
\hline & 8. deney & $18.75 \mathrm{~dB}$ \\
\hline & 9. deney & $20 \mathrm{~dB}$ \\
\hline & 10. deney & $23,01 \mathrm{~dB}$ \\
\hline & 11. deney & $26,99 \mathrm{~dB}$ \\
\hline & 12. deney & $30 \mathrm{~dB}$ \\
\hline
\end{tabular}

Yüksek ve düşük güç kullanıcı ayrımı için eşik seviye değerini $100 \mathrm{~mW}$ olarak seçtik. Dolayısıyla, yeni yöntemde yukarıdaki 15 ikincil kullanıcıdan 6 adedi (koyu renk olanlar) kanal edinme şansına hiçbir zaman sahip olamamaktadır.

Toplam (birincil + ikincil kullanıcıların elde ettikleri) kazanç açısından klasik ve yeni algoritma ile elde ettiğimiz çıktıları karşılaştırdığımızda aşağıdaki gibi sonuç elde ettik. Beklendiği gibi yeni algoritmada kanal kiralama yüzdesi düştüğünden (kanal alabilen ikincil kullanıcı sayısı azaldığından) elde edilen gelir de toplamda düşmektedir. Çıktıları SINR eşik seviyesinin değişimine göre inceledik (şekil 3).

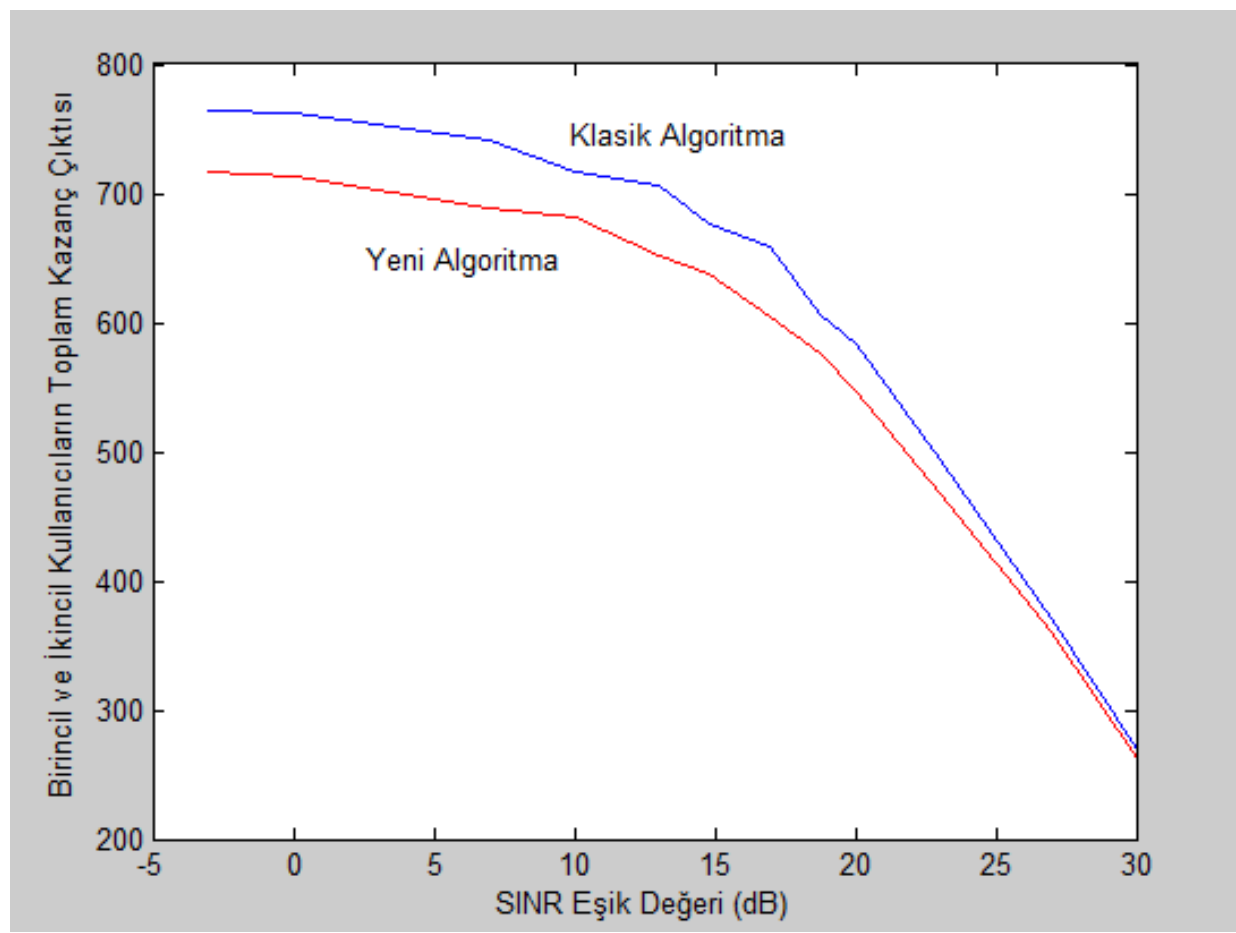

Şekil 3. Klasik ve yeni algoritmamızın toplam kazanç çıktılarının SINR eşik değerine göre değişimi 
Görüldüğü üzere, toplam kazanç yine SINR eşik artışı ile düşmekte, ayrıca yeni algoritmada toplam dağıtılabilen kanal sayısı da azaldığı için toplam gelir de klasik algoritmaya göre düşmektedir. İkincil karşılaştırma olarak alınan kanal sayısına bağlı olarak sistemde ikincil kullanıcıların harcadığı toplam güç seviyelerini karşılaştırdık. Burada her bir ikincil kullanıcının aldığı kanal sayısından yola açarak, aşağıdaki formülle toplam harcanan gücü hesaplıyoruz.

\section{Harcanan güç çarpanı $=\sum($ İkincil kullanıcı gücü * Aldığı kanal sayısı $)$}

Beklendiği üzere yeni algoritmada alınabilen kanal yüzdesi düştüğü için harcanan güç miktarında da düşme görülmektedir. $\mathrm{Bu}$ da yeşil iletişim kapsamında sistemimizin daha enerji verimliği çalıştığını doğrulamaktadır. Şekil 4'te verilen sonuçlar da bunu doğrulamaktadır.

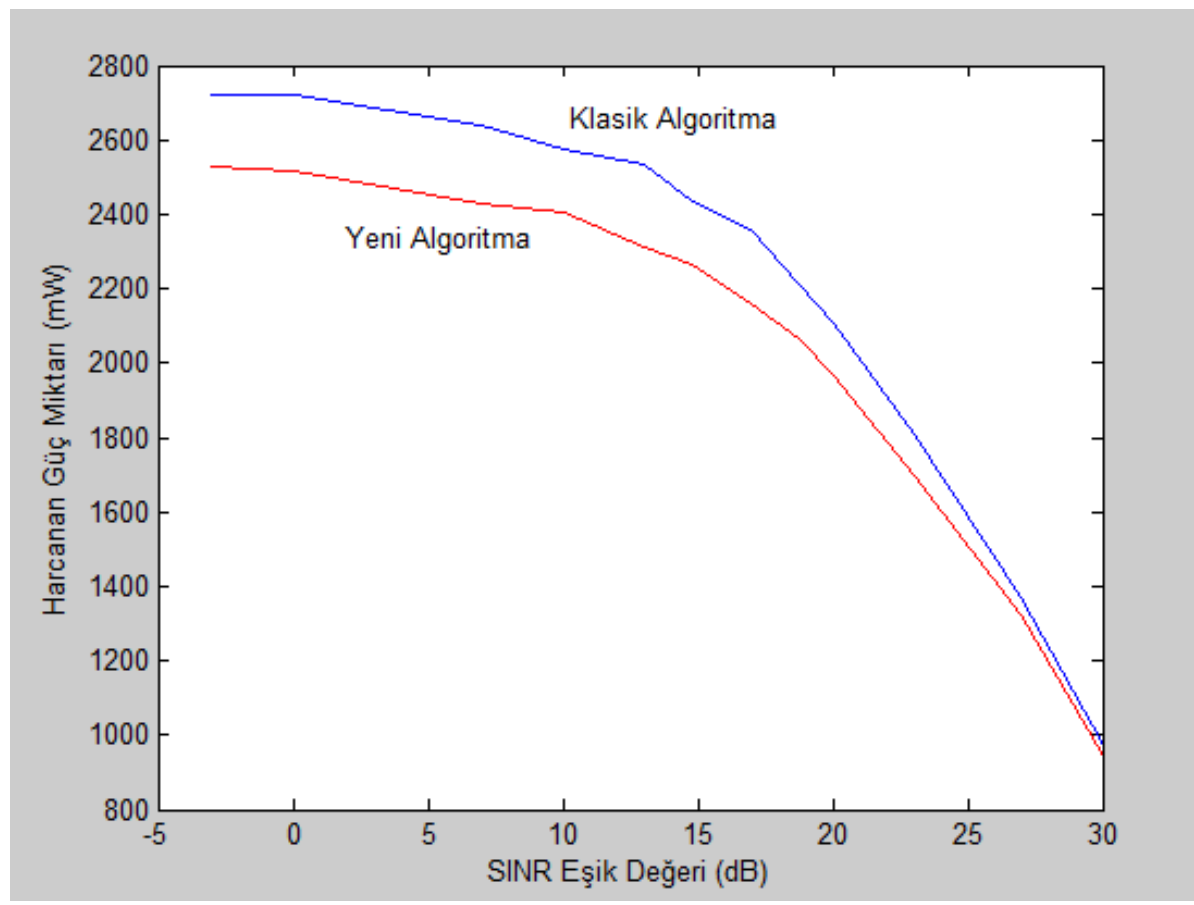

Şekil 4. Klasik ve yeni algoritmamızın harcanan güç miktarlarının kıyaslanması

\section{Sonuçlar ve Gelecek Çalışmalar}

KR sistemlerinin teknik anlamda gerçekleştirilebilmesi ve yaygın olarak kullanılabilmesi henüz pratik olarak gerçekleşmemiş̧ir. Ancak günümüzde gittikçe artan kablosuz veri iletişim imkânlarının kullanım oranlarının devamlı arttığı düşünülürse, yetersiz frekans spektrumu problemine sunacağı katkı akademik, endüstriyel çevrelerin ilgisini çekmektedir. $\mathrm{Bu}$ çalışmada kablosuz iletişimde farklı teknolojileri bir arada çalıştırabilecek, artan kullanıcı sayılarını ve taleplerini mevcut spektrumu verimli ve dinamik olarak kullanmak suretiyle karşılayabilecek niteliklere sahip KR teknolojisi tanıtılmış, bu sistemin temel özellikleri, kullanılan teknikler, mevcut teknolojilerden farklılıkları ve üstünlükleri farklı şekilde sınıflandırılan akademik çalışmalarla incelenmiştir.

Kognitif radyo ve kullanıldığı kognitif radyo ağları, frekans sahasında birincil kullanıcılar adını verdiğimiz lisanslı kullanıcılar tarafından kullanılmayan frekansların, ikincil kullanıcılar olarak isimlendirilen kullanıcılar tarafından geçici kullanımına olanak tanıyarak frekans sahası sıkışıklığı 
problemine bir çözüm getirmektedir. Kognitif radyo amacı itibariyle frekans bandının bilinçli kullanımıyla kullanıcı ihtiyaçlarını karşılamaya çalışmaktadır, bu anlamda yeşildir, çünkü tüketici ortamında kısıtlı kaynakların yönetimi ile enerji verimliliği, enerji tasarrufu ve elektromanyetik yayılım gibi çevre üzerinde doğrudan etkisi olan sorunları çözmeye çalışır.

Bütün çalışmalarda öngörülen KR cihazların kendi donanım ve yazılım özelliklerinin yanı sıra, ağ yönetimine ait kurallar ve yetkiler çerçevesinde değiştirilebilir olduklarıdır. Yine son yıllarda gittikçe önem kazanan SDN (Yazılım Tanımlı Ağlar) konusu büyük ölçüde ağ ortamında kullanılan cihazların veri yönlendirme kabiliyetlerinin yazılımlar aracılığı ile arttırılmasını öngörmektedir. Yapılan bu çalışmalarda belirtilen ve kullanılmakta olan algoritmalara ilave olarak aşağıdaki konular gelecek çalışmalara yön vermesi açısından dikkate alınabilir:

- Frekans sahası algılama ve toplam enerji verimliliği arasındaki ödünleşimi minimize edecek şekilde gücün algılama ve iletim arasında nasıl dağıtılacağı,

- Birincil ve ikincil kullanıcı sayılarıyla orantılı toplam verimliliğin çoklu anten alıcıları veya işbirlikçi çeşitleme gibi daha ileri işaret işleme yöntemleri ile tekrar incelenmesi,

- Gürültü yoğun ortamlarda önerilen yöntemlerin performans değişiklikleri,

- Enerji verimliliği probleminin, özellikle işbirlikçi algılamanın kaçınılmaz olduğu kablosuz ortamlarda ikincil kullanıcılar için adil bir algılama görevi dağıtımı,

- Frekans sahası algılama ve frekans değişim mekanizmalarına dinamik öğrenim tekniklerinin dahil edilmesi,

- Enerji verimliliği için proaktif veya reaktif yaklaşımlar için yeni yöntemler.

Bu çalışmamızdaki en büyük katkı geliştirdiğimiz yeşil ödeme algoritmamızın enerji tüketimini azaltıcı etkisinin yapılan simülasyonlarla ispatlanmasıdır.

\section{Kaynaklar}

[1] Yucek, T. ve Arslan H., "A survey of spectrum sensing algorithms for cognitive radio applications”, IEEE Communications Surveys, 11(1), 116-130, 2009.

[2] Mitola, J. ve Maguire, G. Q., “Cognitive radio: making software radios more personal”, IEEE Personal Communucations. Magazine, 6, 4, 13-18, 1999.

[3] ET Docket No. 03-108, Notice of proposed rule making and order: facilitating opportunities for flexible, efficient, and reliable spectrum use employing cognitive radio technologies, Federal Communications Commission, 2005.

[4] Çiçek, M. Ve Akçam, N., "Bilişsel Radyo Gelişim Sürecinde Telsiz Cihazların Yazılım Açısından Sisteme Uygunluğunun Kontrolü”, ISITES 2014, Karabük, 588-596, 2014.

[5] Neel, J. O., Analysis and design of cognitive radio networks and distributed radio resource management algorithms, Ph.D. dissertation, Virginia Polytechnic Institute and State University, 2006.

[6] Chen, K. C., Peng, Y. J., Prasad, N., Liang, Y. C. Ve Sun,S., “Cognitive radio network architecture: part I - general structure”, Proceedings, 2nd International Conference on Ubiquitous Information Management and Communication, 114-119, 2008. 
[7] Çiçek M., "Bilişsel Radyo Teknolojisi ve Düzenleme Perspektifi”, Bilgi Teknolojileri ve İletişim Kurumu Biliş̧im Uzmanlık Tezi, Ankara, 2011.

[8] http://apps.webofknowledge.com/, (19.04.2016).

[9] Su, H. ve Zhang, X., "Opportunistic energy-aware channel sensing schemes for dynamic spectrum access networks”, IEEE Global Telecommunications, 1-5, 2010.

[10] Han, J., Jeon, W. ve Jeong, D., "Energy efficient channel management scheme for cognitive radio sensor networks”, IEEE Transactions on Vehicular Technology, 60, 4, 1905-1909, 2011.

[11] Palicot, J., "Cognitive radio:an enabling technology for the green radio communications concept", International Conference on Wireless Communications and Mobile Computing: Connecting the World Wirelessly, 489-494, 2009.

[12] Shukla, A. et al., "Cognitive radio technology. A study for Ofcom”, Final Report, QINETIQ/06/00420, Vol. 1, Issue 1.1, 2007.

[13] Haykin, S., "Cognitive radio: brain empowered wireless communications", IEEE Journal on Selected Areas in Communications, 23 (2), 201-220, 2005.

[14] Thomas, R.W., DaSilva, L.A., MacKenzie, A.B., “Cognitive networks”, in: Proc. IEEE DySPAN 2005, 352-360, 2005.

[15] Jondral, F.K., "Software-defined radio basic and evolution to cognitive radio", EURASIP Journal on Wireless Communication and Networking, 2005.

[16] Grace, D., Chen, J., Jiang, T. ve Mitchell, P. D., "Using cognitive radio to deliver green communications", International Conference on Cognitive Radio Oriented Wireless Networks and Communications, 1-6, 2009.

[17] Akyıldı, I.F., Lee, W.Y., Vuran, M.C., Mohanty, S., "A Survey on Spectrum Management in Cognitive Radio Networks”, IEEE Communications Magazine, 46(4), 40-48, 2008.

[18] Zhang, W., Mallik R. and Letaief, K. "Optimization of cooperative spectrum sensing with energy detection in cognitive radio networks", IEEE Trans. Wireless Communications, 8(12), 5761-5766, 2009.

[19] Luo, L., Ghosh, C. and Roym, S. "Joint optimization of spectrum sensing for cognitive radio networks”, Proc. 2010 IEEE GLOBECOM, 1-5, 2010.

[20] Namboodiri, V., "Are cognitive radios energy efficient? a study of the wireless LAN scenario", IEEE 28th International Performance Computing and Communications Conference, 437-442, 2009.

[21] Akyildiz, I.F., Lo.B.F., Balakrishnan R., "Cooperative spectrum sensing in cognitive radio networks: A survey”, Physical Communication (Elsevier) Journal, 4(1), 40-62, 2011.

[22] Ejaz, W., Shah, G. A., Hasan, N. U. I. and Kim, H.S., "Energy and throughput efficient cooperative spectrum sensing in cognitive radio sensor networks", Transactions on Emerging Telecommunications Technologies, 26, 7, 1019-1030, 2015. 
[23] Roblesa, R. S. ve Juarezb, M.C., "Energy efficient random transmission control for cognitive radio systems", Iberoamerican Conference on Electronics Engineering and Computer Science, 7, 79-87, 2013.

[24] Imran, M., Tang, W. ve Tafazolli, R., "Coordination of energy efficient sensing and transmission in cognitive radio networks”, PGNET Liverpool, 2011.

[25] Bourbia, S., Guennec, D. L., Palicot, J., Grati, K. ve Ghazel, A., "Equalizer's use limitation for complexity reduction in a green radio receiver", Journal of Computer Networks and Communications, article ID794202, 15 pages, 2013.

[26] Zhao, N.,Yu, F. R., Sun, H. ve Nallanathan, A., "Energy-efficient cooperative spectrum sensing schemes for cognitive radio networks", Global Communications Conference, 3600-3604, 2013.

[27] Wang, S. ve Wang, C., "Joint optimization of spectrum and energy efficiency in cognitive radio networks”, Digital Communications and Networks, 1, 3, 161-170, 2015.

[28] Xie R., Yu, F. R. ve Ji, H., "Energy-efficient spectrum sharing and power allocation in cognitive radio femtocell networks”, IEEE INFOCOM, 1665-1673, 2012.

[29] Wenjuan, L., Zizhong, Q., Quan, L., Duzhong, Z. and Wenjun,X., "QoE Based Spectrum Allocation Optimization Using Bees Algorithm in Cognitive Radio Networks", Algorithms and Architectures for Parallel Processing, 9528, 327-338, 2015.

[30] Venkatesan1, M., Kulkarni, V. A., ve Menon, R., “Artificial Neural Network based Learning in Cognitive Radio”, Proc. of Int. Conf. on Advances in Communication, Network and Computing, 142-147, 2013.

[31] Qadir J: Artificial intelligence based cognitive routing for cognitive radio networks. http://arxiv.org/abs/

[32] Abbas, N., Nasser, Y., and Ahmad, K.E., "Recent advances on artificial intelligence and learning techniques in cognitive radio networks", EURASIP Journal on Wireless Communications and Networking, 174, 2015.

[33] Di Felice, M., Chowdhury, K., Wu, C., Meleis, W., and Bononi, L.,. "Learning-based Spectrum Selection in Cognitive Radio Ad Hoc Networks”, Proc. of IEEE WWIC'10, Lulea, Sweden, 133145, 2010.

[34] Youssef, M., Ibrahim, M., Abdelatif, M., Chen, L., and Vasilakos, A., "Routing metrics of cognitive radio networks: A survey". IEEE Communications Surveys \& Tutorials, 16(1), 92109, 2014.

[35] Cesana, M., Cuomo,F., Ekici,E., "Routing in cognitive radio networks: challenges and solutions”, Elsevier Ad Hoc Networks Journal, 9 (3), 228-248, 2011.

[36] Rao, K. L., Chakravarthy, C. K. ve Chilukuri, S., "Energy efficient routing in cognitive radio networks: challenges and existing solutions”, Journal on Communication Technology: Special Issue, 6, 1, 2015.

[37] Palicot J., "Cross-layer sensors for green cognitive radio". Ann Telecommun (Springer-Verlag), 67(3-4),171-180, 2011. 
[38] Palicot, J., "Cognitive radio: an enabling technology for the green radio communications concept”. In: IWCMC’09,Leipzig, Germany, 2009.

[39] Palicot, J., Zhang, X., Leray, P. ve Moy, C., "Cognitive radio and green communications: power consumption consideration”, International Symposium on Radio Systems and Space Plasma, 2010.

[40] Palicot, J., Roland, C., "On the use of cognitive radio for decreasing the electromagnetic radiations”, URSI 05, XXVIII General Assembly, New Delhi, India, October 23--29, 2005.

[41] Gur, G., and Alagoz, F., "Green wireless communications via cognitive dimension: an overview”, IEEE Network, 25(2), 50-56, 2011.

[42] Li, L., Zhou, X., Xu, H., Li, Y.G., Wang, D.,and Soong, A., "Energy-efficient transmission in cognitive radio networks", in Proc. IEEE Consumer Commun. and Networking Conf. (CCNC'10), 1-5, 2010.

[43] Chen, Y., Zhao, Q., and Swami, A., "Distributed spectrum sensing and access in cognitive radio networks with energy constraint”, IEEE Trans.Signal Process., 57(2), 783-797, 2009.

[44] Ghadikolaei, H. S., Glaropoulos, I., Fodor, V., Fischione, C. ve Dimou, K., "Energy efficient spectrum sensing and handoff strategies in cognitive radio networks", IEEE Communications Society, 2013.

[45] Sun, H. , Nallanathan, A., Wang, C. X., ve Chen, Y., "Wideband spectrum sensing for cognitive radio networks: a survey”, IEEE Wireless Communications, 20(2), 74-81, 2013.

[46] Karaca, H. M., Kurt, T., Zafer Dicle, S. ve Anarim, E., "Auction-Based Throughput Maximization in Cognitive Radio Networks Under Interference Constraint”, Wireless Personal Communications, Vol 72, Issue 2, 1259-1275, 2013.

[47] Oloyede, A., Grace, D., "Energy Efficient Short Term Spectrum Auction Using the Concept of Green Payments”, Wireless Personal Communications, 2016. 